\title{
STRATEGI BAURAN PEMASARAN WINE SEBAGAI PRODUK PENUNJANG PARIWISATA (STUDI KASUS PT. SABABAY WINERY BALI)
}

\author{
Agatha Fransiska Tarigan ${ }^{1}$, I Nyoman Sudiarta ${ }^{2}$, Ni Putu Eka Mahadewi ${ }^{3}$ \\ ${ }^{1}$ Email: agatha tarigan@ymail.com \\ Program Studi S1 Industri Perjalanan Wisata, Fakultas Pariwisata, Universitas Udayana \\ ${ }^{2}$ Email: sudiarta.nyoman@yahoo.co.id \\ Program Studi S1 Industri Perjalanan Wisata, Fakultas Pariwisata, Universitas Udayana \\ ${ }^{3}$ Email: eka.mahadewi23@gmail.com
}

\begin{abstract}
Recently wine tourism products are being developed in Bali. Bali's Wine is produced from the wineries, processed and produced in Bali which can be used as a tourist activity. This study aims to determine the strengths and weaknesses in wine products marketing and opportunities also, threats and know the strategy and marketing program of wine product that can be applied in PT. Sababay Winery. Data collection techniques used observation, interview, literature study, questionnaire, and documentation. Determination of the sample in this study is to use purposive sampling. Informant determination using key informant. This research use descriptive qualitative data analysi combine with likert scale analysis. The purpose of this study is to determine the characteristics of tourists, to find out the factors those influenced the decision of tourists to buy some souvenirs and also to find the most influenced factors. The methods of collecting data were through observation, interviewed, questionnaire, documentation, and literature study methods. The methods of analysis data were using descriptive quantitative method, through validity test, reliability and analysis of factors those supported by SPSS program 17.0 version. From this research, there are fourteen strength indicators and two indicators of weakness and indicators of opportunity as many as seven indicators and three indicators of threats owned by PT. Sababay Winery. Strategies and marketing programs that can be applied by PT. Sababay Winery is a product creation and development strategy, a strategy to increase wine product promotions, market expansion strategies, and marketing enhancement strategies.
\end{abstract}

Abstrak: Pada saat ini produk pariwisata wine sedang dikembangkan di Bali. Wine Bali dihasilkan dari perkebunan anggur, diolah dan diproduksi di Bali yang dapat dijadikan sebagai kegiatan wisata. Penelitian ini bertujuan untuk mengetahui kekuatan serta kelemahan dalam memasarkan produk wine, peluang serta ancaman yang dimiliki dan mengetahui strategi dan program pemasaran produk wine yang dapat diterapkan di PT. Sababay Winery. Teknik pengumpulan data digunakan observasi, wawancara, studi kepustakaan, kuesioner, dan dokumentasi. Penentuan sampel pada penelitian ini digunakan purposive sampling. Penentuan informan digunakan informan kunci. Teknik analisis data menggunakan analisis data deskriptif kualitatif, dan analisis skala likert. Dari penelitian ini diperoleh indikator-indikator kekuatan sebanyak empat belas indikator serta dua indikator kelemahan dan indikator peluang sebanyak tujuh indikator serta tiga indikator ancaman yang dimiliki oleh PT. Sababay Winery. Strategi dan program pemasaran yang dapat diterapkan PT. Sababay Winery ialah strategi penciptaan dan pengembangan produk, strategi meningkatkan kegiatan promosi produk wine, strategi memperluas pasar, dan strategi peningkatan pemasaran.

Keywords: marketing mix strategy, wine, tourism supporting products. 


\section{PENDAHULUAN}

Dewasa ini pariwisata merupakan salah satu sektor pembangunan yang saat ini sedang digalakkan oleh pemerintah Indonesia, karena pariwisata mempunyai peran yang sangat penting dalam pembangunan khususnya sebagai penghasil devisa negara. Perkembangan pariwisata memegang peran penting dalam menunjang keadaan ekonomi suatu daerah karena memiliki keterkaitan sebagai sumber percepatan pertumbuhan ekonomi daerah. Selain menunjang keadaan ekonomi, pariwisata juga mampu menciptakan kesempatan kerja sehingga mampu mengurangi tingkat kemiskinan. Oleh karena itu diperlukan berbagai faktor untuk meningkatkan kualitas pariwisata, seperti peningkatan strategi dalam menunjang fasilitas, pelayanan, dan peningkatan kondisi daerah tujuan wisata hingga strategi pemasaran pariwisata.

Selain potensi daerah tujuan wisata yang dimiliki oleh Bali, wisata kuliner juga bisa menjadi alternative dalam menunjang pengembangan industri pariwisata. Wisata kuliner saat ini semakin populer di kalangan wisatawan, karena banyak acara di televisi yang mempopulerkan wisata kuliner. Makanan khas Bali yang sangat populer dan diburu oleh wisatawan ialah ayam betutu dan babi guling. Tidak hanya makanan khas Bali yang saat ini sedang dicari oleh wisatawan, minuman khas seperti brem dan arak Bali juga memiliki banyak peminat dari kalangan wisatawan lokal maupun wisatawan asing.

Selain kuliner makanan dan minuman lokal Bali yang populer di kalangan pariwisata, Bali juga memiliki minuman yang sudah mendunia namanya namun tetap berasal dari Bali. Minuman yang namanya sudah mendunia itu ialah wine. Wine merupakan minuman beralkohol yang berasal dari fermentasi buah anggur dan dibuat sesuai dengan tata cara lokal. Dengan adanya wine khas Bali, minuman tersebut sering dipadukan dengan berbagai makanan khas Bali dan banyak wisatawan yang menyukainya.
Di Bali saat ini ada empat perusahaan wine lokal yang memproduksi wine yaitu, PT. Hatten Bali, PT. Sababay Winery, Plaga, dan Cape Discovery. Posisi pasar dari keempat perusahaan tersebut dari yang paling laku di pasaran ialah; posisi pertama ialah PT. Hatten Bali, wine Two Islands milik PT. Hatten Bali memiliki jumlah pembeli tertinggi karena anggur menggunakan anggur impor dari Australia sehingga rasa Two Islands berbeda dengan wine lain yang dimiliki oleh PT. Hatten Bali; kedua Plaga, produk wine dari Plaga yang banyak disukai ialah Sweet Rose karena rasanya manis dan sesuai dengan lidah orang Indonesia; posisis ketiga Cape Discovery, memiliki banyak peminat karena kualitas dari Sauvignon Blanc telah dikaui oleh para ahli wine; dan yang berada di posisi terakhir ialah PT. Sababay Winery karena produk wine milik perusahaan tersebut cocok untuk dipadukan dengan makanan lokal Bali (Hasil wawancara dengan I Komang Adi Priyatna, Wine Shop Bali).

Salah satu pabrik wine di Bali yang mulai berkembang dengan penjualan yang meningkat derastis pada tahun 2017 ialah PT. Sababay Winery. Peningkatan penjualan pada PT. Sababay Winery dapat dilihat pada Diagram 1 sebagai berikut.

Diagram 1. Volume Penjualan Wine di Sababay Winery

Penjualan Wine

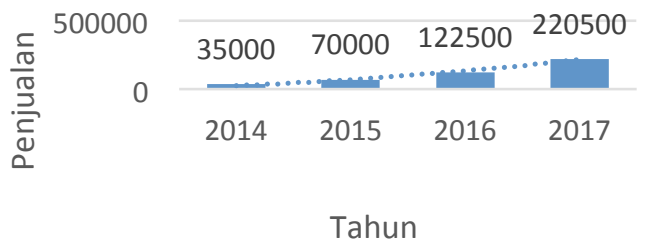

Sumber PT. Sababay Winery 2017

Berdasarkan Diagram 1 Volume penjualan wine pertama PT. Sababay Winery di tahun 2014 sebanyak 35.000 botol kemudian meningkat sebanyak $40 \%$ di tahun 2015 sebanyak 70.000 botol. Pada tahun 2016 penjualan wine di PT. Sababay 
Winery meningkat sebanyak 122.500 botol dan pada pertengahan tahun 2017, penjualan wine di PT. Sababay Winery meningkat derastis $80 \%$ yaitu sebanyak 220.500 botol. Dapat disimpulkan bahwa penjualan wine di PT. Sababay Winery meningkat setiap tahun. Peningkatan ini belum dikatakan sempurna apabila posisi pasar dari PT. Sababay Winery masih berada di posisi terakhir, oleh karena itu perlu dilakukan penelitian mengenai Strategi pemasaran di PT. Sababay Winery agar mampu menaikkan posisi pasarnya.

\section{METODE PENELITIAN}

Lokasi penelitian dilakukan di PT. Sababay Winery Gianyar, Bali. PT. Sababay Winery menjadi lokasi penelitian karena posisi perusahaan tersebut berada di urutan terakhir dari kompetitor lain akan tetapi volume penjualan dari PT. Sababay Winery terus meningkat sehingga perlu meninjau mengenai strategi bauran pemasaran agar mampu berada di posisi teratas di Bali.

Adapun variabel yang diteliti ialah, strategi pemasaran PT. Sababay Winery dengan pendekatan segmentasi pasar yaitu: segmenting, targeting, dan positioning (Kotler, 2001:5). Faktor lingkungan internal dengan tujuh indikator dari 7P unsur bauran pemasaran yaitu: (1) Product, (2)Price (Monroe, 2005), (3)Promotion (Basu Swasta dan Irawan, 1990:349), (4)Place (Kotler, 2000:96), (5)People, (6)Process, dan (7)Physical evidence (Kotler dan Amstrong, 2012:62). Faktor eksternal perusahaan dengan enam indikator yaitu: (1)Analisis Pasar, (2)Analisis Kompetitor. (3)Analisis Pemasok, (4)Analisis Pemerintah, (5)Analisis Teknologi, dan (6)Analisis Ekonomi (Rangkuti, 2013:24).

Jenis data yang digunakan pada penellitian ini ialah data kualitatif dan data kuantitaif (Sugiyono, 2012:1). Sumber data pada penelitian ini ialah data primer dan data sekunder (Moleong, 2005:157). Pada penelitian ini teknik pengumpulan data yang dipakai yaitu: observasi, wawancara, studi kepustakaan, kuesioner, dan dokumentasi (Sugiyono, 2012). Teknik penentuan sampel pada penelitian ini berdasarkan metode purposive sampling (Sugiyono, 2012:117), dengan rumus menurut Suparto (2006) yaitu sebagai berikut:

Sampel $=$ jumlah indikator $\mathrm{x} 5$ sampai 10

Teknik analisis data yang digunakan pada penelitian ini ialah: analisis skala likert (Kusmayadi dan Endar 2000: 47) digunakan untuk menghitung hasil kuesioner, dan analisis matriks SWOT yaitu EFAS IFAS (Rangkuti, 2013:83) digunakan untuk mendapatkan strategi pemasaran yang tepat untuk PT. Sababay Winery.

\section{HASIL DAN PEMBAHASAN}

PT. Sababay Winery merupakan sebuah perusahaan wine yang berada di Bali yang didirikan pada tahun 2010 dan mulai mendapat ijin untuk menjual wine di tahun 2013. PT. Sababay Winery bekerjasama dengan petani anggur yang ada di Buleleng, Bali mereka memborong seluruh anggur dari hasil panen disana. Awal mula PT. Sababay Winery berdiri ialah ketika sang pendiri Sababay yaitu Ibu Mulyati Gozali membeli anggur yang ada di Buleleng saat dia berkunjung ke Bali, menemukan harga anggur yang rendah Ibu Mulyati merasa kurang adil dengan harga tersebut. Harga anggur murah yang dibeli Ibu Mulyati disebabkan oleh karena pengunjung yang jarang membeli anggur sementara hasil pertanian yang dihasilkan di Buleleng kebanyakan ialah buah anggur. Berdasarkan hal tersebut muncul pemikiran dari Ibu Mulyati untuk membuat sebuah usaha yang berbahan dasar buah anggur sehingga meskipun hasil panen anggur berlimpah di Buleleng anggur-anggur tersebut dapat berguna, dengan hal ini juga petani anggur di Buleleng dapat tertolong karena hasil panen tersebut ada yang membeli. Kemudian lahir ide untuk mendirikan perusahaan wine yang berasal dari anggur hasil panen di Bali, diolah dan dikemas sendiri oleh perusahaan tersebut.

PT. Sababay Winery dibangun di lahan seluas dua hektar di daerah Gianyar 
tepatnya di lokasi penghubung Kuta, Denpasar, dan Sanur. PT. Sababay Winery memiliki alat pemroses anggur berkualitas yang diimpor dari Perancis, dan hanya ada satu di Indonesia. Proses pengolahan anggur di PT. Sababay Winery juga dilakukan dengan menggunakan pressing machine vertikal dan horizontal yang terbuat dari bahan stainless steel dan pipa saluran fermentasi. Pabrik pengolahan anggur tersebut didukung dengan manajemen pembuangan (waste), bottling line otomatis, laboratorium, dan berbagai fasilitas pendukung lainnya. Asal nama Sababay diambil dari nama teluk yang berada di Desa Saba yang dekat dengan lokasi perkebunan anggur, sehingga disebut "Saba Bay" yang memiliki arti "Teluk Saba".

Selain menjual produk wine PT. Sababay Winery saat ini menyediakan fasilitas winery visit untuk perusahaan yang bekerjasama dengan PT. Sababay Winery yang kini mulai banyak peminatnya baik dari perusahaan yang bekerjasama dengan PT. Sababay Winery maupun para pengunjung dengan syarat harus melakukan booking terlebih dahulu.

Untuk mempermudah setiap proses kegiatan yang ada di perusahaan PT. Sababay Winery memiliki fasilitas yang berperan sebagai penunjang segala proses kegiatan yang berlangsung. Fasilitas yang dimiliki PT. Sababay Winery ialah: gedung, perangkat komputer, jaringan internet, telepon, perangkat kerja lainnya (mesin print, fotocopy, scanner, faxmile, dan lemari), peralatan dalam pembuatan dan penyimpanan wine, laboratorium pengawasan mutu, manajemen pembuangan limbah yang ramah lingkungan, kebun anggur seluas 80 hektar, dan alat transportasi.

\section{Strategi Pemasaran PT. Sababay Winery 1. Segmentasi Pasar (Segmenting)}

Dalam menentukan strategi
pemasaran di PT. Sababay Winery maka dilakukan penentuan segmen pasar. Dari segi segmentasi pasar geografis PT. Sababay Winery telah menyebar produknya ke berbagai kota di Indonesia yaitu Medan, Pekanbaru, Palembang, Jakarta, Bandung, Semarang, Yogyakarta, Surabaya, Bali, Lombok, Flores, Pontianak, Palangkaraya, Banjarmasin, Balikpapan, Samarinda, Manado, dan Makassar dengan masing masing distributor pada satu kota. Dengan demikian segmentasi PT. Sababay Winery secara umum ialah masyarakat lokal (domestik) dan untuk daerah Bali segmen pasarnya ialah wisatawan domestik maupun mancanegara. Dari segi demografis segmen pasar PT. Sababay Winery ialah orang-orang yang sudah dewasa dan para pekerja.

2.Pasar Sasaran (Targeting)

Pasar sasaran (targeting) yang dimaksud pada penelitian ini ialah tindakan yang dilakukan oleh PT. Sababay Winery dalam memilih satu atau lebih dari satu segmen pasar atas pemasaran produk wine yang dimiliki PT. Sababay Winery. Pasar sasaran (targeting) di PT. Sababay Winery ialah kaum millennial, orang-orang yang sudah dewasa, para pekerja, serta wisatawan domestik maupun wisatawan mancanegara.

\section{Posisi Pasar (Positioning)}

Posisi pasar (positioning) yang dimaksud pada penelitian ini berupa citra (image) yang dimiliki oleh PT. Sababy Winery di tengah-tengah konsumen atau wisatawan serta industri lainnya yang diajak bekerjasama dengan PT. Sababay Winery. Saat ini PT. Sababay Winery berada di posisi terakhir dari empat perusahaan wine lokal Bali, setelah PT. Hatten Bali, Plaga, dan Cape Discovery (Sumber: Wine Shop Bali).

\section{Bauran Pemasaran PT. Sababay Winery}

1. Product (Produk)

Produk ialah segala sesuatu yang ditawarkan oleh sebuah perusahaan yang bertujuan untuk memuaskan kebutuhan serta keinginan konsumen baik yang berwujud (tangible) maupun tidak berwujud (intangible). PT. Sababay Winery memproduksi tujuh jenis wine (lihat Lampiran 8 Gambar 8.2) memiliki rasa bervariasi sesuai dengan kandungannya. 
Adapun produk yang dimiliki PT. Sababay Winery ialah:

a. Moscato d'Bali

Moscato d'Bali merupakan wine yang berasal dari anggur muscat saint vallier, mengandung $8 \%$ alkohol, dan berwarna lime green.

b. Ludisia

Dari anggur alphonse Lavallee, wine ludisia mengandung $11 \%$ alkohol dan warna yang dimiliki wine ludisia berwarna rubyred.

c. Reserve Red

Reserve red terbuat dari olahan anggur alphonse, dengan 12\% kandungan alkohol, dan berwarna rubyred.

d. Black velvet

Wine ini berasal dari olahan anggur alphonse lavallee, mengandung $11 \%$ alkohol, dan warna yang dimiliki wine black velvet yaitu berwarna ruby red.

\section{e. Pink Blossom}

Berbahan dasar anggur alphonse lavallee, dengan kandungan $10 \%$ alkohol, dan warna wine pink blossom berwarna salmon pink.

\section{f. White Velvet}

Wine white velvet memiliki bahan dasar anggur muscat saint vallier, mangandung $11 \%$ alkohol, dan berwarna light yellow dengan lime green hues.

g.Mascetti

Mascetti terbuat dari anggur alphonse lavalle dan shiraz, memiliki kandungan alkohol 19\%, dan berwarna ruby.

2. Price (Harga)

Price (Harga) merupakan variabel penentu dalam hal persaingan pemasaran produk. Harga yang diberikan oleh PT. Sababay Winery ialah berdasakan mata uang USD (\$) dan Rupiah (Rp) dimana harga yang ditetapkan untuk satu produk wine merupakan harga yang cukup mampu untuk bersaing di pasaran. Adapun daftar harga yang ditawarkan untuk setiap produk wine dari retail yaitu tanpa service (off trade) dan hotel dengan service (on trade) ialah sebagai berikut:

a. Moscato d'Bali

Produk Moscato d'Bali ditawarkan retail dengan harga mulai dari Rp. 240.000 hingga Rp. 290.000 dan untuk harga hotel dengan service yang diberikan harga mulai dari Rp. 350.000 hingga Rp. 450.000.

\section{b.Ludisia}

Wine ludisia dengan harga mulai dari Rp. 220.000 hingga Rp. 250.000 apabila dibeli dari retail yaitu tanpa service dan untuk hotel dengan service mulai dari harga $\mathrm{Rp}$. 300.000 hingga Rp. 400.000.

c. Reserve Red

Untuk harga retail, Reserve Red ditawarkan dengan harga mulai dari $\mathrm{Rp}$. 200.000 hingga Rp. 230.000 dan di hotel ditawarkan dengan harga mulai dari $\mathrm{Rp}$. 280.000 hinga Rp. 380.000

\section{d. Black velvet}

PT. Sababay Winery memberikan harga dari retail mulai dari Rp. 180.000 hingga Rp. 210.000 dan apabila di hotel harga yang ditawarkan mulai dari Rp. 250.000 hingga Rp. 350.000 .

\section{e. Pink Blossom}

Harga retail pada produk wine pink blossom dimulai dari harga Rp. 180.000 hingga Rp. 210.000, dan dari hotel yang disajikan dengan service diberikan dengan harga mulai Rp. 250.000 hingga Rp. 350.000 .

f. White Velvet

Untuk harga dari retail, produk wine white velvet memiliki harga mulai dari $\mathrm{Rp}$. 180.000 hingga Rp. 210.000. Pembelian di hotel dengan menggunakan service, white velvet diberikan harga mulai dari $\mathrm{Rp}$. 250.000 hingga seharga Rp. 350.000 .

g.Mascetti

Wine mascetti yang merupakan produk baru dari PT. Sababay Winery diberikan harga retail mulai dari Rp. 400.000 hingga Rp. 450.000 tanpa menggunakan service sedangkan harga yang ditawarkan di hotel yang menggunakan service diberikan harga mulai dari Rp. 500.000 hingga $\mathrm{Rp}$. 1.500 .000 .

3. Promotion (Promosi)

Promotion atau promosi ialah salah satu kegiatan yang dilakukan untuk memperkenalkan dan menawarkan produk kepada pasar, promosi merupakan faktor penentu keberhasilan suatu perusahaan dalam memasarkan produknya. PT. Sababay Winery melakukan berbagai cara 
untuk memperkenalkan produk wine yang mereka miliki agar dikenal oleh pasar dan agar laku terjual yaitu dengan cara memperkenalkan di media sosial seperti instagram dan facebook, melakukan barter dengan radio, melalui majalah, presentasi langsung kepada konsumen dan outlet, mengikuti berbagai acara dengan membuka booth yang memberikan wine testing untuk menarik minat konsumen, mempromosikan produk melalui website yang dapat diakses di www.sababaywinery.com.

Pemesanan produk, winery visit, dan informasi dapat dilakukan melalui telepon di (021) 30329781 dan melalui email di info@sababaywinery.com dengan minimal order sebanyak 720 botol dan minimal 10 orang untuk melakukan pemesanan kegiatan winery visit.

4. Place (Saluran Distribusi)

PT. Sababay Winery terletak di Jalan Bypass Prof Ida Bagus Mantra NO.333X Banjar Lodpeken, Gianyar, Bali Indonesia. Letak dari PT. Sababay Winery dapat dikatakan mudah untuk ditemukan dan dijangkau. Saluran distribusi pemasaran produk wine yang dimiliki oleh PT. Sababay Winery saat ini memiliki kerjasama dengan beberapa tempat perusahaan seperti Carrefour Sunset, Gelael Supermarket Kuta, Hotel Santika Delta Dewata Ubud, Swissbelhotel, Food Hall Sunset, Red \& Wine Seminyak, Red \& Wine Sanur, Grand Hyat, Hard Rock Cafe dan beberapa perusahaan lain yang membantu peningkatan volume penjualan wine kepada konsumen di pasaran.

5. People (Personal)

People yang dimaksud pada penelitian ini ialah karyawan atau orang-orang yang terlibat secara langsung maupun tidak langsung dengan wisatawan/ konsumen. Konsumen yang ingin membeli wine tidak bertatap langsung dengan karyawan di PT. Sababay Winery karena perusahaan tersebut akan memberikan produknya kepada distributor yang akan melalukan transaksi kepada konsumen yang membeli satu atau beberapa botol saja. Untuk winery visit di PT. Sababay Winery, karyawan secara langsung melayani para tamu atau wisatawan saat kegiatan winery visit berlangsung.

6. Process (Proses)

Proses pada penelitian ini ialah kegiatan yang menunjukkan setiap tahapan pelayanan yang diberikan kepada wisatawan atau konsumen selama melakukan proses pembelian wine dan dalam kegiatan winery visit di PT. Sababay Winery. Adapun proses pembelian produk wine ialah sebagai berikut:

1.Calon konsumen melakukan pemesanan melalui telepon ataupun email kepada karyawan PT. Sababay Winery, dengan mengisi biodata yang diberikan oleh PT. Sababay Winery dan infromasi mengenai jenis wine apa yang dipilih oleh konsumen. Jumlah minimal order di PT. Sababay Winery yaitu minimal sebanyak 720 botol.

2.Jangka waktu pembayaran yang diberikan kepada konsumen PT. Sababay Winery ialah selama 30 hari sampai maksimal 60 hari.

3. Selanjutnya calon konsumen akan menerima konfirmasi dari PT. Sababay Winery apabila semua persyaratan telah dipenuhi.

4.Kemudian barang akan dikirim ke alamat yang diberikan oleh konsumen melalui pengantaran dengan kendaraan darat hingga pengiriman melalui pesawat udara.

Untuk pemesanan kegiatan winery visit di PT. Sababay Winery ada beberapa langkah yang harus dilakukan, yaitu sebagai berikut:

1.Wisatawan/ calon pengunjung melakukan pemesanan melalui telepon atau email, karyawan menjelaskan apa saja kegiatan yang akan dilakukan saat kegiatan winery visit berlangsung. Memberitahu kepada karyawan kapan waktu yang diinginkan oleh wisatawan/ calon pengunjung, tujuannya apa, dan memberitahukan apabila ada permintaan khusus (ada tidaknya wine taste dan lunch). PT. Sababay Winery menetapkan bahwa apabila ingin melakukan kegiatan winery visit, jumlah orang yang dapat mengikuti winery visit yaitu minimal 10 orang. 
Karyawan dan wisatawan/ calon pengunjung akan melakukan kesepakatan terkait harga yang ditentukan sesuai dengan kegiatan yang diinginkan oleh wisatawan/ calon pengunjung.

2. Selanjutnya wisatawan/ calon pengunjung akan menerima konfirmasi dari pihak PT. Sababay Winery apabila semua syarat dan kesepakatan telah terpenuhi.

7. Physical Evidence (Bukti Fisik)

Pada penelitian ini yang dimaksud dengan bukti fisik ialah merupakan lingkungan fisik dimana jasa dan produk disampaikan. Bentuk fisik dari PT. Sababay Winery dalam menunjang kualitas pelayanan yang diberikan kepada pelanggan ialah dengan penampilan karyawan yang rapi dan sopan sehingga membuat pelanggan nyaman, lingkungan perusahaan yang selalu bersih dan rapi dengan dekorasi yang menarik, fasilitas kantor yang memadai seperti kantor pada umumnya, dimana terdapat toilet yang bersih, tempat parkir yang cukup untuk wisatawan/ konsumen yang datang mengunjungi Sababay Winery, keadaan pabrik yang steril dan bersih, serta keadaan restaurant yang bersih dan rapi.

\section{Analisis Lingkungan Internal dan Lingkungan Eksternal PT. Sababay Winery}

Dari hasil penelitian mengenai penilaian responden yang mengkonsumsi dan berkunjung ke PT. Sababay Winery, maka akan diperoleh hasil kekuatan dan kelemahan yang dimiliki oleh PT. Sababay Winery. Penelitian ini menggunakan 100 responden untuk memberi penilaian, maka berdasarkan hasil penelitian kekuatan dan kelemahan yang dimiliki oleh PT. Sababay Winery dapat dilihat pada Tabel 1 berikut.

Tabel 1. Hasil Peniliaian Responden terhadap Lingkungan Internal PT. Sababay Winery

\begin{tabular}{lll}
\multirow{2}{*}{ No } & \multicolumn{1}{c}{ Faktor Internal } & \\
\cline { 2 - 3 } Kekuatan & $\begin{array}{l}\text { Rata- } \\
\text { rata }\end{array}$ \\
\hline \multirow{3}{*}{1} & $\begin{array}{l}\text { Variasi produk wine } \\
\text { yang ada di PT. } \\
\text { Sababay Winery }\end{array}$ & 3,0 \\
\hline
\end{tabular}

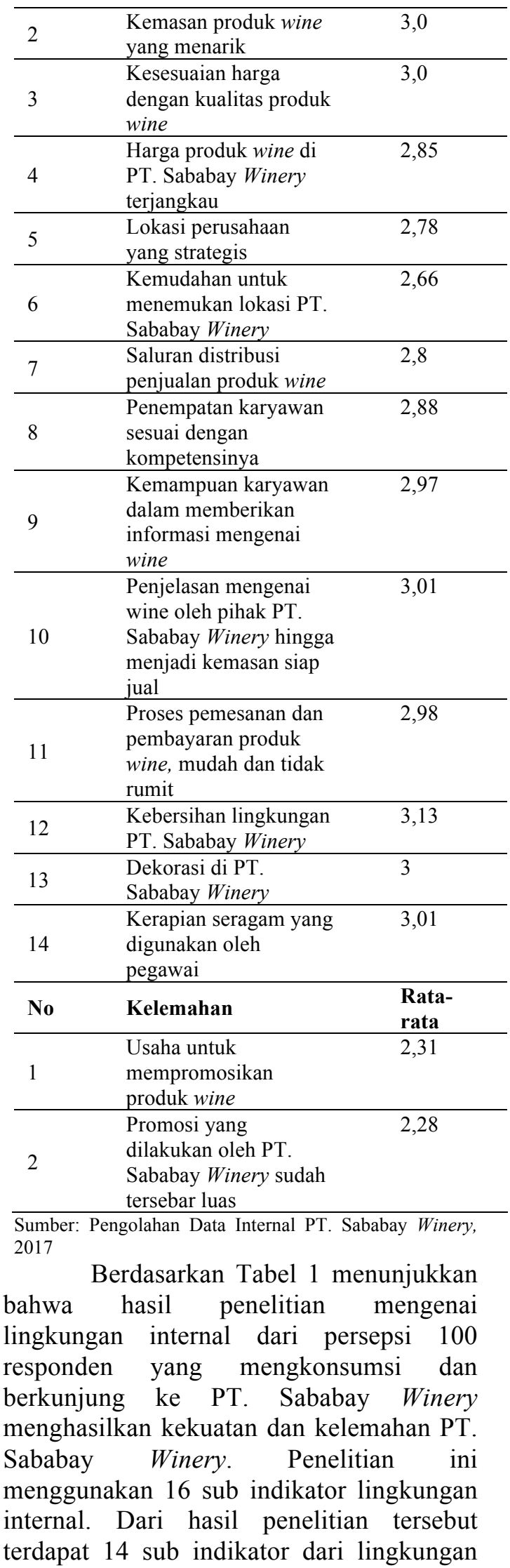


internal yang menjadi kekuatan dan 2 sub indikator dari lingkungan internal yang menjadi kelemahan. Hasil dari penelitian lingkungan internal telah diidentifikasi, selanjutnya kekuatan dan kelemahan yang dimiliki PT. Sababay Winery akan dimasukkan kedalam analisi SWOT.

Berdasarkan perolehan hasil analisis dari responden yang memberikan penilaian terhadap lingkungan eksternal pada PT. Sababay Winery sebanyak 5 responden dari ahli akademisi yang mengerti mengenai pemasaran, maka perolehan mengenai peluang dan ancaman PT. Sababay Winery dapat dilihat pada Tabel 2 berikut

Tabel 2. Hasil Penilaian Responden Terhadap Lingkungan Eksternal PT. Sababay Winery

Faktor Eksternal

\begin{tabular}{|c|c|c|}
\hline $\mathrm{NO}$ & Peluang & $\begin{array}{l}\text { Rata- } \\
\text { rata }\end{array}$ \\
\hline 1 & $\begin{array}{l}\text { Jumlah peminat } \\
\text { produk wine semakin } \\
\text { meningkat }\end{array}$ & 3,6 \\
\hline 2 & $\begin{array}{l}\text { Semakin banyak } \\
\text { perusahaan yang } \\
\text { menjual produk wine }\end{array}$ & 3,2 \\
\hline 3 & $\begin{array}{l}\text { Terjalinnya kerjasama } \\
\text { pemasok dengan } \\
\text { perusahaan wine }\end{array}$ & 3,4 \\
\hline 4 & $\begin{array}{l}\text { Keterlibatan birokrasi } \\
\text { pemerintah terhadap } \\
\text { pajak perusahaan wine }\end{array}$ & 2,8 \\
\hline 5 & $\begin{array}{l}\text { Keterlibatan } \\
\text { pemerintah terhadap } \\
\text { ijin untuk menjalankan } \\
\text { usaha wine }\end{array}$ & 2,8 \\
\hline 6 & $\begin{array}{l}\text { Pemanfaatan } \\
\text { kemajuan teknologi } \\
\text { informasi dalam } \\
\text { kegiatan pemasaran } \\
\text { produk wine }\end{array}$ & 3,4 \\
\hline 7 & $\begin{array}{l}\text { Tingkat perekonomian } \\
\text { masyarakat Indonesia } \\
\text { yang meningkat }\end{array}$ & 3 \\
\hline NO & Ancaman & $\begin{array}{l}\text { Rata- } \\
\text { rata }\end{array}$ \\
\hline 1 & $\begin{array}{l}\text { Penggunaan alat } \\
\text { canggih dalam proses } \\
\text { pembuatan wine, yaitu } \\
\text { mesin pembuat wine }\end{array}$ & 2,4 \\
\hline
\end{tabular}

\begin{tabular}{llc}
\hline 2 & $\begin{array}{l}\text { Nilai tukar rupiah } \\
\text { yang melemah }\end{array}$ & 2,2 \\
\hline 3 & Fluktuasi harga BBM & 2,2 \\
\hline
\end{tabular}

Sumber: Pengolahan Data Internal PT. Sababay Winery, 2017

Dari Tabel 2 diatas menunjukkan bahwa hasil penilaian responden terhadap lingkungan eksternal PT. Sababay Winery dari 5 responden yang merupakan ahli akademisi menghasilkan peluang dan ancaman perusahaan. Indikator yang digunakan pada kuesioner lingkungan eksternal tersebut sebanyak 10 indikator, terdapat 7 indikator dari lingkungan eksternal yang menjadi peluang dan 3 indikator yang menjadi ancaman dari lingkungan eksternal. Hasil penelitian lingkungan eksternal tersebut telah diidentifikasi, selanjutnya peluang dan ancaman tersebut akan dimasukkan ke dalam analisis SWOT.

\section{Analisis SWOT PT. Sababay Winery}

Analisis SWOT merupakan metode yang digunakan untuk menganalisis kondisi PT. Sababay Winery berdasarkan faktor internal yaitu sebagai strengths (kekuatan) dan weakness (kelemahan), serta faktor eksternal yaitu sebagai opportunities (peluang) dan threats (ancaman) yang diperoleh dari hasil penelitian di perusahaan Sababay Winery. Berdasarkan analisis matriks SWOT yang telah dilakukan, yaitu kombinasi dari faktor internal dan faktor eksternal diperoleh empat alternatif strategi, yaitu strategi SO, strategi WO, strategi ST dan strategi WT. Adapun strategi-strategi tersebut ialah sebagai berikut:

1. Strategi SO

Strategi ini dibuat berdasarkan jalan pikiran perusahaan, yaitu dengan memanfaatkan seluruh kekuatan untuk memanfaatkan peluang sebesar-besarnya. Strategi SO yang ditempuh oleh PT. Sababay Winery dengan menciptakan serta mengembangkan produk wine yang berkualitas dan menarik.

2. Strategi WO

Strategi WO ini diterapkan 
berdasarkan pemanfaatan peluang yang ada dengan cara meminimalkan kelemahan yang ada. Strategi WO yang ditempuh oleh PT. Sababay Winery adalah meningkatkan kegiatan promosi produk wine.

3. Strategi ST

Strategi ST menggunakan kekuatan yang dimiliki oleh perusahaan untuk mengatasi ancaman. Strategi ST yang ditempuh oleh PT. Sababay Winery yaitu dengan cara memperluas pasar agar produk wine lebih dikenal.

4. Strategi WT

Strategi WT didasarkan pada kegiatan yang bersifat defensif dan berusaha meminimalkan kelemahan yang ada serta menghindari ancaman. Strategi WT yang ditempuh oleh PT. Sababay Winery yaitu dengan melakukan strategi peningkatan pemasaran.

\section{Strategi dan Program Pemasaran Produk Wine yang dapat Diterapkan PT. Sababay Winery}

1. Strategi Penciptaan dan Pengembangan

Produk, yaitu sebagai berikut:

a. Menciptakan produk berbahan dasar wine dengan kandungan rasa wine terbaik milik PT. Sababay seperti cokelat dengan rasa wine moscato d'Bali. Dengan adanya inovasi tersebut, calon konsumen/ wisatawan akan penasaran untuk mencoba cokelat mocato d'Bali tersebut sehingga akan menarik minat calon konsumen/ wisatawan untuk membeli.

b.Pengembangan produk wine dapat dilakukan dengan mengubah desain kemasan yang lebih menarik agar mampu menarik minat calon konsumen/wisatawan untuk membeli produk wine sebagai produk pariwisata.

2.Strategi Meningkatan Kegiatan Promosi

Produk Wine yaitu dengan cara sebagi berikut:

a. Meningkatkan kegiatan periklanan (advertising) melalui sosial media seperti instagram, facebook, dan twitter yang saat ini sedang banyak digunakan oleh masyarakat. Selain sosial media, meningkatkan kegiatan periklanan di media cetak juga sangat penting seperti memasukkan iklan di majalah lokal.

b. Mengikuti dan menjadi sponsor dalam sebuah acara seperti acara musik, grand opening sebuah bar atau restaurant dengan menawarkan serta memberi potongan harga kepada para tamu yang hadir.

3. Strategi Memperluas Pasar

a. Memperluas kerjasama dengan tempattempat yang bagus dan terkenal seperti hotel, bar, restoran, dan tempat perbelanjaan yang belum dijangkau oleh PT. Sababay Winery.

b. Menjalin hubungan kerjasama dengan distributor baru di berbagai kota yang belum dijangkau oleh PT. Sababay Winery. PT. Sababay Winery memiliki distributor resmi yang berada di berbagai kota yang ada di Indonesia seperti, Medan, Pekanbaru, Palembang, Jakarta, Bandung, Semarang, Yogyakarta, Surabaya, Bali, Lombok, Flores, Pontianak, Palangkaraya, Banjarmasin, Balikpapan, Samarinda, Manado, dan Makassar, akan tetapi masih ada beberapa kota di Indonesia yang belum menjalin kerjasama dengan PT. Sababay Winery. Oleh karena masih banyak kota yang belum menjalin kerjasama dengan PT. Sababay Winery maka perlu dilakukan survey ke berbagai kota untuk mengetahui minat masyarakat terkait produk wine seperti beberapa kota di Papua.

c. Menjalin kerjasama dengan perusahaan di luar negeri yang dapat memperluas pasar PT. Sababay Winery

\section{Strategi Peningkatan Pemasaran}

a. Melakukan survey kepada konsumen di beberapa tempat yang menjual produk wine untuk mengetahui faktor keinginan dan kebutuhan konsumen saat ini yang berguna untuk meningkatkan kualitas produk di PT. Sababay Winery.

b.Melakukan survey harga dengan berkunjung ke tempat-tempat yang menjual wine agar harga di PT. 
Sababay Winery dapat bersaing di pasar.

c. Membuat jadwal perubahaan tata letak dan dekorasi di kantor, ruang makan, serta ruangan untuk menjamu tamu agar dapat memberi kenyamanan kepada konsumen/ wisatawan saat berkunjung untuk membeli produk maupun mengikuti winery visit di PT. Sababay Winery.

d.Meningkatkan kualitas pelayanan yang diberikan kepada calon konsumen saat melakukan pemesanan, transaksi, dan memberikan informasi yang dibutuhkan. Meningkatkan kualitas pelayanan terhadap wisatawan/ pengunjung yang berkunjung saat melakukan kegiatan winery visit.

\section{SIMPULAN DAN SARAN Simpulan}

Berdasarkan pembahasan mengenai 7P bauran pemasaran (Marketing mix) yang dipadukan dengan analisis SWOT (Strenght/ kekuatan, Weakness/ peluang, Opportunities/ peluang, dan Threats/ ancaman) yang dimiliki oleh PT. Sababay Winery maka diperoleh beberapa kesimpulan pada penelitian ini. Penelitian ini dapat disimpulkan sebagai berikut.

a. Indikator-indikator kekuatan yang dimiliki oleh PT. Sababay Winery ialah variasi produk wine yang ada di Sababay Winery, kemasan produk wine yang menarik, kesesuain harga dengan kualitas produk wine, harga produk wine di PT. Sababay winery terjangkau, lokasi perusahaan yang strategis, kemudahan untuk menemukan lokasi PT. Sababay Winery, saluran distribusi penjualan produk wine, penempatan karyawan sesuai dengan kompetensinya, kemampuan karyawan dalam memberikan informasi mengenai wine, penjelasan mengenai wine oleh pihak PT. Sababay Winery hingga menjadi kemasan siap jual, proses pemesanan dan pembayaran produk wine mudah dan tidak rumit, kebersihan lingkungan PT. Sababay Winery, dekorasi di PT. Sababay Winery, dan kerapian seragam yang digunakan oleh pegawai. Indikator kelemahan yang dimiliki oleh PT. Sababay Winery ialah usaha untuk mempromosikan produk wine, dan promosi yang dilakukan oleh PT. Sababay Winery.

b.Indikator-indikator peluang yang dimiliki oleh PT. Sababay Winery ialah Jumlah peminat produk wine semakin meningkat, semakin banyak perusahaan yang menjual produk wine, terjalinnya kerjasama pemasok dengan perusahaan wine, keterlibatan birokrasi pemerintah terhadap pajak perusahaan wine, keterlibatan pemerintah terhadap ijin untuk menjalankan usaha wine, pemanfaatan kemajuan teknologi informasi dalam kegiatan pemasaran produk wine, dan tingkat perekonomian masyarakat Indonesia yang meningkat. Indikator ancaman yang dimiliki oleh PT. Sababay Winery ialah Penggunaan alat canggih dalam proses pembuatan wine, yaitu mesin pembuat wine, nilai tukar rupiah yang melemah, dan fluktuasi harga BBM.

Strategi dan program pemasaran produk wine yang dapat diterapkan di PT. Sababay Winery ialah:

a. Menciptakan produk berbahan dasar wine dengan kandungan rasa wine terbaik milik PT. Sababay seperti cokelat dengan rasa wine moscato d'Bali.

b.Pengembangan produk wine dapat dilakukan dengan mengubah desain kemasan yang lebih menarik agar mampu menarik minat calon konsumen/wisatawan untuk membeli produk wine sebagai produk pariwisata.

c. Meningkatkan kegiatan periklanan (advertising) melalui sosial media instagram, facebook, dan twitter serta meningkatkan kegiatan periklanan di media dengan memasukkan iklan di majalah lokal.

d.Mengikuti dan menjadi sponsor dalam acara musik, grand opening sebuah bar atau restaurant dengan menawarkan serta memberi potongan harga kepada para tamu yang hadir. 
e. Memperluas kerjasama dengan tempattempat yang bagus dan terkenal seperti hotel, bar, restoran, dan tempat perbelanjaan yang belum dijangkau oleh Sababay Winery.

f. Menjalin hubungan kerjasama dengan distributor baru di berbagai kota di Indonesia yang belum dijangkau oleh PT. Sababay Winery.

g.Menjalin kerjasama dengan perusahaan di luar negeri yang dapat memperluas pasar PT. Sababay Winery.

h.Melakukan survey kepada konsumen di beberapa tempat yang menjual produk wine untuk mengetahui faktor keinginan dan kebutuhan konsumen saat ini yang berguna untuk meningkatkan kualitas produk di PT. Sababay Winery.

i. Melakukan survey harga dengan berkunjung ke tempat-tempat yang menjual wine agar harga di PT. Sababay Winery dapat bersaing di pasar.

j. Membuat jadwal perubahaan tata letak dan dekorasi di kantor, ruang makan, serta ruangan untuk menjamu tamu agar dapat memberi kenyamanan kepada konsumen/ wisatawan saat berkunjung untuk membeli produk maupun mengikuti winery visit di PT. Sababay Winery.

k. Meningkatkan kualitas pelayanan yang diberikan kepada calon konsumen saat melakukan pemesanan, transaksi, dan memberikan informasi yang dibutuhkan. Meningkatkan kualitas pelayanan terhadap wisatawan/ pengunjung yang berkunjung saat melakukan kegiatan winery visit.

\section{Saran}

Berdasarkan hasil dan pembahasan yang diperoleh pada penelitian ini, penulis mencoba untuk memberikan saran-saran yang dapat membantu PT. Sababay Winery dalam memasarkan produk wine kepada calon konsumen/ wisatawan. Berikut beberapa saran yang dapat diberikan kepada PT. Sababay Winery, yaitu:

a. Meningkatkan kegiatan pemasaran yang lebih aktif seperti bekerjasama dengan media cetak majalah nasional maupun internasional untuk membuat iklan di majalah tersebut. Meningkatkan pemasaran melalui media sosial seperti instagram, facebook dan twitter yang saat ini sedang banyak digunakan. Meningkatkan system booking online melalui website yang dimiliki PT. Sababay Winery untuk memudahkan pelanggan dalam memesan dan memilih produk wine yang diinginkan.

b.PT. Sababay Winery harus sering mengikuti dan menjadi sponsor di berbagai acara seperti acara musik atau konser, grand opening bar atau restaurant dengan menawarkan produk wine pada saat acara berlangsung sehingga produk wine yang dimiliki oleh PT. Sababay Winery lebih dikenal oleh pasar dan mampu menarik wisatawan yang berkunjung ke Bali untuk membeli produk wine tersebut.

c.PT. Sababay Winery sebaiknya meningkatkan fasilitas, inovasi atau kreatifitas, serta kualitas wine dan bekerjasama dengan travel-travel yang ada di Bali sehingga PT. Sababay Winery dapat dijadikan sebagai tourism attraction yang mengarah pada wine tours. Dengan demikian program winery visit yang telah diterapkan di PT. Sababay Winery dapat berkembang menjadi wine tours dan mampu mendatangkan wisatawan domestik maupun internasional sehingga jumlah kunjungan wisatawan yang berkunjung ke Bali meningkat.

d.Memperluas pangsa pasar dengan menjalin kerjasama dengan distributor di berbagai kota di Indonesia seperti di Papua, dan menjalin kerjasama dengan perusahaan luar negeri sehingga produk wine lokal dari Bali yang dimiliki oleh PT. Sababay Winery mampu go international. 


\section{Kepustakaan}

Irawan. B.S. (1990). Manajemen Pemasaran Modern, Edisi Kedua. Yogyakarta : Liberty

J. Supranto. (2006). Pengukuran Tingkat Kepuasan Pelanggan : Untuk Menaikkan Pangsa Pasar

Kotler, P. (2000). Manajemen Pemasaran. Jakarta : PT.Prenhalindo. . (2001). Manajemen Pemasaran Analisis, Perencanaan, Implementasi, dan Kontrol. Jakarta: PT. Prehallindo.

Kusmayadi. (2004). Statistika Pariwisata Deskriptif. Jakarta : PT. Gramedia Pustaka Utama.

Manroe, Allard C.R. Van Riel et al. (2005). Marketing Antecedent of Industrial Brand Equity: An Empirical Investigation in Spesialty Chemical. Industrial Marketing Management.

Moleong, Lexy, J. (2005). Metode Penelitian Kualitatif. Edisi Revisi. Bandung : PT. Remaja Rosdakarya.

Rangkuti, F. (2010). Analisis SWOT Teknik Membedah Kasus Bisnis. Jakarta : Gramedia Pustaka Utama.

Sugiyono. (2012). Metode Penelitian Kuantitatif Kualitatif dan $R \& D$. Bandung : Alfabeta. 